\title{
Promoting patient autonomy: Perspectives of occupational therapists and nurses
}

P Govender, PhD; D Naidoo, $\mathrm{PhD}$

Discipline of Occupational Therapy, School of Health Sciences, University of KwaZulu-Natal, Durban, South Africa

Corresponding author: P Govender (naidoopg@ukzn.ac.za)

Background. There has been a turn in the last decade towards autonomy in patient care. Promoting patient autonomy is required as a collaborative endeavour between the patient, healthcare professionals and the families and caregivers of patients. Our current discourse demonstrates patient autonomy as essential.

Objective. To explore the concept of autonomy in nurses' and occupational therapists (OTs)' individual and collective practice as healthcare professionals Methods. The study followed a qualitative explorative approach. Fourteen nurses and 12 OTs from 6 facilities in KwaZulu-Natal Province of South Africa were recruited into the study. Following ethical approval, and dependent on the availability of participants, data were collected via focus groups, triad and individual semi-structured interviews and qualitative questionnaires. Data were analysed using inductive thematic analysis per profession initially, and then later merged to develop themes.

Results. Two major themes emerged that spoke to the deconstruction of autonomy and deterrents to the promotion of autonomy in clinical practice. An individualistic view of autonomy was embedded within the participants' understanding of the concept. It included the patient's right and ability to selfdetermine or direct treatment and various interventions, having appropriate guidance and the relevant information to make decisions, and opportunities to self-determine their course of treatment. Patient-related and organisational factors served as barriers to the promotion of autonomy.

Conclusion. By analysing the experiences of autonomy in practice of these two professions, we may be able to establish new ways of understanding how professional practice can truly become patient-centred and transition from an individualistic understanding of autonomy towards viewing autonomy as relational.

Afr J Health Professions Educ 2020;12(4):224-226. https://doi.org/10.7196/AJHPE.2020.v12i4.1366

Autonomy is a complex concept, and although universal, varies widely in its meaning and interpretation between different healthcare professions. ${ }^{[1]}$ The basic definition of autonomy is 'freedom from external control or influence and independence' and is synonymous with the concepts of 'selfdetermination' and 'freedom. ${ }^{\text {'2] }}$ Within the medical realm, autonomy is defined as a personal decision that is void of controlling interferences that prevent meaningful choice, ${ }^{[3]}$ and the agreement to respect another's right to self-determine a course of action and support independent decisionmaking, thereby highlighting the concept of client-centred care. ${ }^{[4]}$

Apart from these definitions, the clinical application of autonomy is not merely allowing patients to make their own decisions, but incorporating respect for the individual's right to self-determination, and creating the necessary conditions for autonomy. ${ }^{[4]}$ The proposition of autonomy as individualistic has been widely recognised, with a more recent definition of personal autonomy as 'self-rule free of controlling interferences by others. ${ }^{\text {'[] }}$ Relational autonomy, on the other hand, considers autonomy as socially embedded, and with a view that self-determination is both defined and pursued in a social context, which influences the opportunities a patient has to express or develop autonomy. ${ }^{[6]}$

There has been a turn in the last decade towards autonomy in patient care. Promoting patient autonomy is required as a collaborative endeavour between the patient, healthcare professionals and families and caregivers of patients. ${ }^{[7]}$ Often, clinical practice is standardised with routine care; the patient's identity disappears, ${ }^{[8]}$ a patient is often considered a passive participant, ${ }^{[9]}$ patients are immobilised in decision-making and the relationship between the nurse and patient is based on the premise that everything is done for the patient, but without the patient. ${ }^{[8]}$

Our current discourse demonstrates patient autonomy as essential. Hence in this study we sought to explore how nurses and occupational therapists (OTs) consider autonomy in their individual and collective practice as healthcare professionals.

\section{Methods \\ Design and sampling}

Within a qualitative explorative approach, nurses and OTs from five public hospitals and one private hospital located in KwaZulu-Natal, South Africa, were purposively recruited into the study. ${ }^{[10]}$ The hospitals were selected based on (i) a high patient turnover; (ii) the presence of acute care; and (iii) the provision of physical rehabilitation services and the presence of rehabilitative healthcare providers. In total, the sample comprised 26 participants, 12 occupational therapy participants and 14 nurse participants.

\section{Data collection}

Data collection methods were dependent on the availability and willingness of recruited participants. OT participants were involved in a triad interview $(n=3)$ and two focus groups $(n=5 ; n=4)$, while the nursing participants were involved in two individual semi-structured interviews $(n=2)$, a triad interview $(n=3)$, a focus group $(n=5)$ and use of an open-ended 
qualitative questionnaire $(n=4)$. The inclusion of the interview questions in a questionnaire was implemented in order to accommodate those nursing staff who could not avail themselves for an interview or focus group, but who wanted to provide their perspectives on the topic.

\section{Selection criteria and demographic profile of participants}

Participants were required to have an active registration with their regulatory bodies, work experience of more than 2 years in an acute physical setting and exposure working with each of the other professions. The mean (standard deviation) age of participants in the study was 34 (9.4) years for OTs and 39.4 (12.8) years for nurses. The majority of OTs held a Bachelor's degree $(n=9 ; 75 \%)$, while the majority of nurses had a nursing diploma $(n=11 ; 79 \%)$. Gender distribution of the sample favoured females; OTs $(n=12 ; 100 \%)$ and nurses $(n=13 ; 93 \%)$, which can be noted as a limitation in the lack of diversity in the sample.

\section{Data analysis}

The focus groups and interviews were audio-recorded and transcribed. Responses to the open questionnaires were collated. Data were analysed inductively via thematic analysis within each professional group, following the first four steps outlined by Braun and Clarke ${ }^{[11]}$ prior to data being merged at the level of naming and renaming themes (step 5) by patternmatching, thus ensuring source triangulation. ${ }^{[10,11]}$

Ethical approval was granted by the School of Health Sciences, UKZN (ref. no SHSEC005) and by the Health Research and Knowledge Management Directorate of the Department of Health (ref. no. HRKM 126/15), and informed consent was solicited from all voluntary participants. The right to withdraw without prejudice as well as the right to privacy and confidentiality was adhered by use of pseudonyms, de-identified demographics and password-protected files. Trustworthiness was maintained by ensuring credibility by peer-briefing (especially during data analysis), investigator and source (nurses and OTs) triangulation. For dependability, an audit trail (of processes and decisions taken as well as ensuring bracketing) were used as strategies to maintain rigour in the study. ${ }^{[10]}$

\section{Results}

The coded data resulted in two broad emergent themes that spoke to the deconstruction of patient autonomy and deterrents to the promotion of autonomy.

\section{Deconstructing patient autonomy}

A basic understanding of patient autonomy that focused on patient choice and promoting patient independence was observed. The participants' definitions of autonomy encompassed being more independent with basic activities of daily living (ADL), returning to previous roles and offering patients 'choice'. This can be attributed to the fact that both professions are embedded in patient-centredness, and therefore naturally fostering the promotion of patient autonomy. Reference to Batho Pele principles ${ }^{[12]}$ was also made:

'To preserve their autonomy we need to make sure they have a right to refuse or accept therapy beforehand.' Emily, OT (OT focus group 2)

'Having a say in what is provided and what own goals are.' Carly, OT (OT focus group 2)

'Sometimes patients give up, [but] once they [find] they can do things for themselves, they begin to gain confidence physically and spiritually? (Nurse, questionnaire)

'Part of our Batho Pele principles is to give patients a choice.' Belinda, OT (OT focus group 1)

The OTs described their position within the multidisciplinary team (MDT) as not always visibly delineated, but conveyed their primary roles in promoting autonomy as translated into ensuring functional independence. The nurses equally expressed this view. Nurses were seen to encourage autonomy related to personal management and advocating for the patient as the centre of nursing care:

'Having the ability to just choose for them self and direct where they want to go in their treatment.' Ashley, OT (OT triad interview)

'With them gaining their independence, we let them do things for themselves, we let them bath themselves if they can or if they can't we assist them ... we are there for them should they need to be pushed a little. Lindiwe, Nurse (Nurse Focus Group)

\section{Deterrents to promoting patient autonomy}

Barriers to promoting patient autonomy, which were either patientrelated or organisation-related, were reported. Family involvement and the self-perception of patients of their situation contributed to a lack of empowerment and independence. The adoption of a 'sick role' while in hospital undermined the ability of patients to act more autonomously, or as their skills and abilities would allow. Participants postulated that the community perception of a nurse, that is as someone who cares and nurtures, is responsible for the execution of all ADL tasks in the best interests of patients. The idea was raised that this community perception prevents nurses from optimally promoting patient autonomy, and patients from actively working towards the attainment of independence.

'The difficulties are not from the patients themselves, but it's always related to the relatives', Zanele, nurse (nurse focus group)

'They feel because they sick and in the hospital they not allowed to have a say. Carly, OT (OT focus group 2)

'When they need to go to the bathroom, even when they can go to the bathroom, they ask for a bed pan just because their relatives are there ... when they were using a bed pan here, they will go home and be given nappies and they come back and they have a bigger problem.' Zanele, nurse (nurse focus group)

The issues around understaffing and burnout among nurses, patient attitudes and general resource limitations, especially in the public healthcare system, that impede their ability in promotion of autonomy among patients were recognised:

'They work long hours and there is a high burnout factor.' Uvira, OT (OT focus group 1)

'Patients are constantly calling and demanding and often very rude to them. Hannah, OT (OT focus group 2)

'Sometimes the patients have attitude with the nurses.' Nokuthula, nurse (nurse focus group)

\section{Conclusion}

In this study, we set out to determine how both OTs and nurses enacted autonomy in the clinical setting. In any health system, strategies that aim 
to humanise and improve the quality of care of patients are paramount, and in keeping with the ethical responsibility of health professionals. With this, the shift towards patient-centred care, as well as the rejection of medical paternalism, have led scholars towards alternative models that emphasise patient autonomy. ${ }^{[13]}$

Patient-centredness is a concept embedded in both the occupational therapy and nursing professions, making both professions suitable for a role in the promotion of patient autonomy. Nurses are encouraged to value patients' decisions, listen and advocate, ${ }^{[8]}$ while OTs essentially engage patients in occupation, thus enabling participation and promoting autonomy. ${ }^{[1,15]}$

By critical examination in this empirical study, we argue that the individualistic view of autonomy has been embedded within the participants' understanding of autonomy. This notion of patient autonomy included the patient's right and ability to self-determine or direct treatment and various interventions, having appropriate guidance and the relevant information to make decisions, and opportunities to self-determine their course of treatment. Both professions support the notion that the concept of autonomy is related to independence. ${ }^{[4,14]}$ Thus, it is evident that both the occupational therapy and nursing professions have embedded the concept of client-centredness and independence, which contributes towards the promotion of patient autonomy.

Notwithstanding this, several obstacles were noted in the promotion of autonomy in this study. While the OTs spoke of marginal hurdles related to their promotion of autonomy, nurses extensively described barriers experienced. Tensions appear to remain among these healthcare professionals, and from the nursing literature, we are acutely aware of how the biomedical model has resulted in the undervaluing of nurses' contributions toward holistic patient care. ${ }^{[8]}$ Largely, nurses have been considered the patient's advocate owing to the emotional and physical care provided, ${ }^{[16]}$ and as agents of patient safety. ${ }^{[8]}$

While agreeing that autonomy is a product of more than just the individualistic view, this study reiterates the need for consideration of the relational and social components in the process of complex decision-making in autonomy. ${ }^{[6]}$ From this study, it was difficult to extrapolate aspects related to how relational autonomy translated to practice for both professions. The challenge of relational autonomy as a moral and ethico-legal principle and threat to patient choice has been noted in the available literature. ${ }^{[1,6,7,17]}$
Future studies should, therefore explicate a more holistic perspective of autonomy, and yield possible strategies that could serve as enablers to the MDT towards authentic patient-centred practice.

\section{Declaration. None.}

Acknowledgements. The authors acknowledge S Cresswell-George, A Kaka, N Mlaba and T Wanless for their contributions to the study.

Author contributions. PG and DN were responsible for the conceptualisation of the study, data analysis and drafting and critical review of the manuscript.

Funding. None.

Conflicts of interest. None.

1. Killackey T, Peter E, Maciver J, Mohammed S. Advance care planning with chronically ill patients: A relational autonomy approach. Nurs Ethics 2019;27(2):360-371. https://doi patients: A relational auto

2. Chalker S, Weiner E. The Oxford Dictionary of English Grammar. Oxford: Oxford University Press, 1998. https:// doi.org/10.1093/acref/9780192800879.001.0001

3. Pantilat S. Autonomy vs beneficence. San Francisco: UC San Francisco, 2008. http://missinglink.ucsf.edu/lm/ ethics/content\%20pages/fast_fact_auton_bene.htm (accessed 29 April 2020).

4. American Nurses Association. Nursing World - Autonomy. 2011. http://www.nursingworld.org MainMenuCategories/ANAMarketplace/ANAPeriodicals/OJIN/Columns/Ethics/Ethics-and-Pain-Management html (accessed 29 April 2020).

5. Beauchamp TL. Making principlism practical: A commentary on Gordon, Rauprich and Vollman. Bioethics 2011;25(6):301-303. https://doi.org/10.1111/j.1467-8519.2011.01908.x

6. Sherwin S, Winsby M. A relational perspective on autonomy for older adults residing in nursing homes. Health Expectations 2010;14(2):182-190. https://doi.org/10.1111/j.1369-7625.2010.00638.x

7. Jacobs G. Patient autonomy in home care: Nurses' relational practices of responsibility. Nurs Ethics 2018;26(6):1638-1653. https://doi.org/10.1177/0969733018772070

8. Molina-Mula J, Peter E, Gallo-Estrada J, Perelló-Campaner C. Instrumentalisation of the health system: An examination of the impact on nursing practice and patient autonomy. Nurs Inq 2017;25(1):e12201. https:// An examination of the imp
doi.org/10.1111/nin. 12201

9. Truglio-Londrigan M. The patient experience with shared decision-making. J Infusion Nursing 2015;38(6):407-418. https://doi.org/10.1097/nan.0000000000000136

10. Patton MQ. Qualitative Research and Evaluation Methods: Integrating Theory and Practice. Newbury Park, Ca. Sage, 2014.

1. Braun V, Clarke V. Using thematic analysis in psychology. Qual Res Psychol 2006;3(2):77-101. https://do org/10.1191/1478088706qp063oa

2. South Africa. White Paper on transformation of the public services. Pretoria: Government Printer, 1995. https: $/$ www.gov.za/sites/default/files/gcis_document/201409/183401.pdf (accessed 11 July 2020).

13. Kilbride MK, Joffe S. The new age of patient autonomy. JAMA 2018;320(19):1973. https://doi.org/10.1001/ jama.2018.14382

14. American Occupational Therapy Association. About occupational therapy. 2015. https://www.aota.org/AboutOccupational-Therapy.aspx (accessed 29 April 2020).

15. World Federation of Occupational Therapy. Defining occupation. https://www.wfot.org/about/aboutoccupational-therapy\#: :text=Definition $\% 20 \% 22$ Occupation $\% 22$,and $\% 20$ are $\% 20$ expected $\% 20$ to $\% 20 \mathrm{~d}$ (accupational-therapy 11 July 2020)
(access

16. Bird AW. Enhancing patient well-being: advocacy or negotiation? J Med Ethics BMJ 1994;20(3):152-156. https:// doi.org/10.1136/jme.20.3.152

17. Dove ES, Kelly SE, Lucivero F, Machirori M, Dheensa S, Prainsack B. Beyond individualism: Is there a place for relational autonomy in clinical practice and research? Clin Ethics 2017;12(3):150-165. https://do org/10.1177/1477750917704156

Accepted 20 August 2020. 